\title{
Three Texts, One Applicant-Identities Constructed in Taoci Email Communication
}

\author{
Lin Xiao ${ }^{1}$ \\ ${ }^{1}$ School of Foreign Languages, Jiangxi University of Finance and Economics, Nanchang, China \\ Correspondence: Lin Xiao, NO. 1200 Lushanzhongdadao, Nanchang City, Jiangxi Province, China.
}

Received: December 14, 2021

Accepted: January 23, 2022 Online Published: February 17, 2022

doi:10.5539/ells.v12n1p95

URL: https://doi.org/10.5539/ells.v12n1p95

\begin{abstract}
This research taps into the identity construction in "Taoci" email, a discursive practice popular among Chinese study-abroad applicants. Following a qualitative approach, we focus on one Chinese student's emails to the same American professor. English Taoci emails and interviews have been collected as research data. Detailed linguistic analysis has been proceeded with the distinctive linguistic features of pronoun usage, "pronoun+predicate" pattern, evaluative vocabulary, discourse content and speech acts. Three relational identities have been found: $I_{(\text {maxium })}$ identity, $I_{(t o \text { you }}$ identity, and $I_{(\text {(and you }}$ identity based on the linguistic features. The interview transcripts are used to scaffold the dynamic discursive building in the emails. It is hoped that this study would contribute to discussion on discourse identity and shed light on intercultural student-faculty email communication in the e-world.
\end{abstract}

Keywords: Taoci, discourse, email communication, relational identity

\section{Introduction}

“Taoci”, written in Chinese characters as “套磁”, originally means building interpersonal relationship with other persons for practical purposes, mainly through linguistic means. This word is deeply rooted in Chinese traditional culture, which regards guanxi (interpersonal relationship) as an important capital in social networking (Xiao \& Gao, 2015). With the rising tide of oversea education application in mainland China, the word of "Taoci email" refers specifically to applicants' personal (English) email contacts with their targeted foreign supervisors so as to increase their admission and scholarship opportunities (Baidu Baike) (Note 1). However, it is never alleged Taoci as an absolute guarantee for a successful application, i.e., the perlocutionary effect of the speech act. For applicants, Taoci means initiative efforts to convince the targeted supervisor of their competent candidacy on the international higher education market. Thus, they need to be very careful in what and how to write in their email.

Researches on English email written by non-native English speakers have tended to problematize non-native English learners as less pragmatically successful (Hartford \& Bardovi-Harlig, 1996; Economidou-Kogetsidis, 2011). However, English learners, putting aside their linguistic and pragmatic inadequacy, could still play the communication game well, particularly for those language learners of a higher proficiency. Furthermore, "When a person begins a mediated or immediate encounter, he already stands in some kind of social relationship to the others concerned..." (Goffman, 1967, p. 41). Taoci email acts as a stage for applicants to present more real "selves" to their supervisors besides those required official document. Taking EFL/ESL learners as successful email writers, this present research focuses on how the discursive details of Taoci email are carefully manipulated by Chinese English learners to present themselves in relation to a high-stakes other.

\section{EFL/ESL Email Writing}

Researches have abounded on English email between students and teachers since email has become one of the most convenient means for communication (Danielewicz-Betz, 2013; Sheer \& Fung, 2007) in order to "get stuff done" (Merrison et al., 2012). Since the current research is on the email by a Chinese student to a Caucasian professor in the US, we mainly review the literature on English email of EFL/ESL learners.

\subsection{The Deficit View of EFL/ESL Emailers}

Many researchers keep a pedagogical concern in studying email-writing to come up with practical advice for teaching English as a second or foreign language. Biesenbach-Lucas, S. has made much contribution to the email 
comparison between English natives and non-natives. Biesenbach-Lucas and Weasenforth (2001) applied Blum-Kulka and Olshtain's CCSARP framework to non-native speakers' and native speakers' email requests to faculty and found that only small differences in the degree of directness of the e-requests (i.e., request in email) were found between the two groups.

Biesenbach-Lucas (2007) applied the CCSARP framework to examine the degree of directness and the politeness features of students' email. Not surprisingly, combinations of syntactic modifiers were used by native speakers in high imposition requests while non-native speakers failed to make use of a combination of devices and were modified primarily through the use of the past tense, downtoners and the marker "please". Economidou-Kogetsidis (2011) examined the request email from English learners to faculty in a Greek university. The research claimed that non-native speakers used direct request, little downgraders, improper forms of address and omitted necessary greetings and closings in email writing. These pragmatically inappropriate uses would inflict negative impression upon native English speakers.

Chen (2001) examined the differences between Taiwanese (NNSs) and American (NSs) graduate students in their e-mail to request for an appointment, writing recommendation letter and giving special consideration. NNSs were reported more of pragmatic infelicities due to being too direct in raising requests. Zhu (2012) compared the politeness strategies used by English learners in request emails solicited by specific tasks between English major and non-English major students in mainland China. The research implied that both groups seemed to exhibit inadequate sociopragmatic competence and pragmalinguistic knowledge in writing English email. Likewise, Pan (2011) found that due to the unequal status between students and faculty, students tended to be indirect in general and demonstrated less capability of employing certain syntactic devices like downgraders in requests.

Such researches have problematized non-native English learners as less pragmatically successful and usually proposed at the end to involve email writing into syllabus design or to cultivate cross-language pragmatic competence or cross-cultural skills. However, such researches have downplayed the fact that English learners, putting their grammatical and pragmatic inadequacy aside, could still play the "communication" game smartly, particularly for those of a higher proficiency.

\subsection{The Success View of EFL/ESL Emailers}

Block (2002) argued for the good demonstration of pragmalinguistic competence of non-native learners of English at an advanced level. His research participants were able to use various strategies in the email, to accommodate their email in different contextual interactions and to choose between formal and informal language uses. Chen (2003), in a longitudinal research on English email practiced by two Chinese in USA, drew in speech act, politeness and CDA in analyzing the power relation and identity construction in email. Research participants were reported to make changes in institutional email writing with regards to discourse style, message length, message structure, and request strategies, demonstrating high communicative competence.

Chen (2015) investigated the efficacy of email-pragmatics instruction to develop L2 students' literacy in English email requests to faculty. Students were reported to make significant gains after the instruction in terms of the greater use of concrete subjects, appropriate greetings, proper self-identifications, and closing moves, which meant the instruction was effective on the post-test than on the pre-test. This is a pioneering study to cultivate students' digital literacy in intercultural communication. Taking the perspective of English as Lingua Franca, Chen, Rau and Rau (2015) edited a book titled "Email Discourse Among Chinese Using English as a Lingua Franca", which filled in the gap of the few-researched area of written ELF in Chinese academia.

As a first try to explore Taoci discourse, Xiao and Gao (2015) started from a capable communicator perspective. They have connected Taoci email with its original sense and discussed what communicative strategies were performed in Chinese applicants' Taoci email. They have drawn out the guanxi Taoci strategies used in Chinese students' email, which resort to interpersonal relations and was associated with the original sense of Taoci in Chinese culture. Nevertheless, Taoci has harvested a positive connotation of acknowledging the endeavors to achieve personal goals. For instance, the "academic Taoci" strategy refers to actively showing an applicant's academic competence and research ability in email to convince the targeted supervisor. Xiao (2016) drew on L2 investment and Bourdieu's theory of practice to examine what Taoci was as "doing things with words" in Chinese students' study-abroad application and in what sense speech act was investment into the applicants' imagined identities.

Generally, intellectual heeds have been less adequately paid to how these "inadequate" learners use their language resources to construct a practical email-er identity. As Taoci email interaction moves on, emailers' identity may exhibit situational adaptability, which has rarely been investigated before. The present article 
attempts to analyze the same emailer presenting different selves to the same correspondent and reveal the adaptability of linguistic features against situational changes.

\section{Relational Identity in Discourse}

This research has taken a more constructivist stance towards the applicant identity construction in relation to the applicantee and focused on the relational identity in Tracy's identity coordinate. Relational identity "refers to the kind of relationship that a person enacts with a particular conversational partner in a specific situation" (Tracy, 2002 , p. 19). A spectrum of discursive practices can be analyzed for identity construction: person-referencing practices, speech acts, sounds of speech, language selection, interaction structures, directness style, narratives, stance indicators. "..., not all identities are equally salient or relevant in different social interactions or at different points in the same social interaction. The relevance of identities is contingent on the participants' self-orientation and ascription-by-others" (Zhu, 2014, p. 111). As context changes, aspects of an identity may vary accordingly, particularly for the identities built upon discursive features.

In email correspondences, the invisibility between the sender and recipient leaves a great space for identity construction. Turkle (1995, p. 177) argued that "when we step through the screen into virtual communities, we reconstruct our identities on the other side of the looking glass". Markley (1992) showed that English learners' writer identities were more creative and more self-expressing in email exchanges. The asynchronous nature of email communication (Herring, 2002) gives Taoci doers enough space to construct a desirable image in relation with their target supervisors. The present research aims to explicate the linguistic features for identity construction and to give a more complete picture about Chinese applicants' Taoci discourse.

\section{Research Method}

The present research tries to answer the following questions: (1) What identities are constructed in the Chinese applicant's Taoci emails? (2) How are the identities and linguistic features adapted to situational changes?

\subsection{The Research Participant}

The participant in the present research has been renamed Ming. In 2013, he was still a fourth-year college student at a prestigious university located in mainland China (K University). He majored in physics as an undergraduate and learned English for more than ten years. His TOEFL score was just above 100 out of a total 120. His GRE performance met the requirement set for international students in the US. He had then received a $\mathrm{PhD}$ program offer with graduate fellowship from a well-known university in southern American (W University). His supervisor, Professor Smith, is a Caucasian American.

\subsection{Data Description}

Two types of data were collected: naturally occurring Taoci email texts and face-to-face interview with the email writer. Ming offered those Taoci email texts which he felt safe and comfortable to share. Each email was labeled with "M-email" plus the email sequence number and stored in the researcher's personal computer. Then face-to-face interviews were arranged based on a careful reading through all his email. The interview took place at a coffee shop nearby his campus. To protect the informant's privacy, pseudonymity has been applied to all the proper names in the data.

Ming shared with me eight pieces of email, ranged from April 2013 to April 12 2014, sent to Professor Smith. The shortest email contains 33 words and the longest 333 words. Three email texts are chosen for the current study because each of them portrays a complete self-representation, as it will be shown later. Based on the email content, the researcher conducted two in-depth interviews with Ming respectively on April 20th, 2014 and December 5th, 2014. The interviews were intended semi-structured, but covering topics about the students' own application experience, writing Taoci email to supervisors, supervisor's email response, and self-reflection during this process. The interviews were conducted in Chinese and were audio-recorded upon permission. A 66-minute audio and a 90-minute audio were obtained and transcribed by the researcher soon after the interview. The first interview transcription turns out 12,886 Chinese characters and the second 19,996. An overview of the data is presented in Table 1. 
Table 1. Data overview

\begin{tabular}{lllll}
\hline Data & Label & Date obtained & Words contained in email body part & Total \\
\hline Email & M-email 1 & Apr. 17, 2014 & 269 English words & 872 English words \\
& M-email 4 & & 270 English words & \\
& M-email 6 & & 333 English words & \\
\multirow{2}{*}{ Interview } & Interview 1 & Apr. 20, 2014 & 12,286 Chinese characters & 32,282 Chinese characters \\
& Interview 2 & Dec. 5, 2014 & 19,996 Chinese characters & \\
\hline
\end{tabular}

\subsection{Data Analysis Method}

The three email texts are analyzed at lexical, semantic and pragmatic level. At the lexico-grammar level, the usage of pronoun and subject+predicate are examined. At the lexico-semantics level, the usage of appraisal terms (Martin \& Rose, 2007) has been analyzed, denoting emotion, judgment, appreciation as well as their accompanied graduation elements. Built upon the lexicon and semantic content, the pragmatic force of speech acts is tackled.

The interview transcripts are introduced in the discussion to scaffold the textual findings. Elements are generalized to explain why the applicant identity was and how it evolved across the texts. Situational changes, addressee's reaction, interactional progress, and participant's self-reflection were found crucial for the explanation. The researcher has attached much importance to "how the research participant thought about this or that" in identity discussion by bringing the interview episodes after the linguistic analysis.

\section{Identities Construction Varying across Texts}

Three types of relational identities are constructed based on the ensemble of linguistic features. $I_{\text {(maxium) }}$-identity refers to a predominant focus on "who I am", with the least concern about the specific supervisor. $I_{(\text {to you })}$-identity portrays an applicant deeply attracted by and willing to work for "the" supervisor. $I_{(\text {and } y o u}$-identity means that the applicant positions himself as a qualified collaborator to the supervisor. All of the three types have an "I" as the center, mainly because the email texts are about self-representation, but at the same time they are relational because the "I"-s are tailored to a particular audience: Professor Smith the gatekeeper. In the following discussion, all "I" means the applicant and "you" the supervisor.

\section{$5.1 \mathrm{I}_{\text {(maxium) }}$ identity in M-Email 1}

Ming wrote his first email to Professor Smith on June 24, 2013, far before the application process officially started as the fall term application starts on September each year. There are four paragraphs, with the first introducing personal academic interest, the second listing previous work, the third repeating his interest and making inquiries, and the last delivering appreciation.

\subsubsection{Dominant "I"-subject}

The most distinctive feature is the prominence of "I"-subject throughout the whole email. The "subject+predicate" of each clause is list as follows:

Table 2. Subject+predicate string in M-email 1 (clause-based)

\begin{tabular}{lll}
\hline Para. & Subject+predicate & Total \\
\hline Para. 1 & I am...; I am preparing...; I read...; I find...; my previous research is...; I find...; my experience... may enable...; \\
Para. 2 & I did...; I published...; I am ...; (my) patent is ...; I won...; I have ...; \\
Para. 3 & I'm ...; I intend ...; Would you...; would you...; \\
Para 4 & Thank you...; I am ...
\end{tabular}

Among the 19 subjects in all clauses, there are 13 "I"-subjects. Even among the left 6 subjects, 3 subjects are related with Ming himself: his previous research, his experience and his patent. It leaves a deep impression on the reader that this email delivers the sole information of the sender, thus maximizing "who I am".

The whole text is imbued with "I" as the agent doing all the work at present, in the past and in the future. However, in terms of the academic work, all predicates are oriented to the past and the present, without the future. For example, "I did some research on photonic crystal fiber ...", "I published two papers", "(my) patent is under processing", "I won the first prize...", and "I have a relatively profound knowledge". These contents further testify that Ming focused on self-representation, i.e., the "I", maximizing his self-image as much as possible. By contrast, there is little mention about the supervisor except referring to Professor Smith's recent 
publication, with the article names not in the email body part, but as a kind of footnote at the end.

Ming had no overlapping with Professor Smith and knew him only from the faculty homepage on the Internet. To the supervisor, Ming has been in the dark. It is high time for Ming to stage himself to the center in order to get a $\mathrm{PhD}$ program, even though it is only an email contact. Thus, the text replete with "I" subjects indicates Ming's full agency to get his applicant identity known to the stranger. On the other hand, the apparently rigid use of "I" subjects may also allude to Ming's English learner identity.

\subsubsection{Implicit Self-Representation and Downgrading Evaluation}

Regarding Ming's self-evaluation, this work is done in an implicit way or even a downgrading manner. First, there are few attitudinal terms about self-acknowledgement, but only an objective narration of facts: Ming's previous research work, published papers, winning awards and applying for a patent. This flags Ming's research ability without clear articulation. Second, even when Ming made an evaluation about himself, it is done in an effacing way. For example:

(1) ... my experience that accumulated during previous study may enable me a competent researcher.

(2) ... I did some research focused on ...

(3) I ... have a relatively profound knowledge on Chemistry.

The modal verb of "may" discloses less possibility, and compromises Ming's alleging a competent researcher. The downgrading adjective "some" implies that Ming didn't do much work before. The adverb of "relatively" preceding "profound" indicates that Ming's knowledge on chemistry is just satisfying, not that "profound". Actually, Ming did have rich research experience, because he started to work in the lab from his third year and published two academic papers, which is an exceptional accomplishment for an undergraduate. He is an excellent student in Chemistry, since the first prize on National Chemistry Competition in China demonstrates advanced level of chemistry knowledge as he mentioned in the second Interview.

I was originally enrolled in the chemistry major because I won the prize. I studied in the Chemistry department for one semester. I knew well what was taught there and I don't need to study anymore. So I decided to transfer to my present major (Interview 2).

Ming's "past" proves that he is a competent candidate. Even Professor Smith replied him that "I'm convinced you would thrive here".

The low-profile exhibition of personal ability might relate to the general tendency that Chinese students are usually not willing to thrust themselves, particularly in front of high-status holders, like a professor. Being modest and being humble is a more preferable approach in this kind of "upward communication" (Ho, 2010), from students to supervisors. However, this downplaying characteristics, as we will see later, finds no such affordance in the other two emails.

\subsubsection{Shadowing "I \& You"}

At the foregoing analysis lies the conclusion that this email is "I"-focused. Another proof is a palpable shadowing of the dyad of "I" towards "You".

First, although Ming mentioned twice that he was very interested in the professor's research area, his main purpose seems to be confined to "asking information about PhD enrolling" as both the email title and email content shows. It is only a request of information, instead of being enrolled as a fellow.

(4) Email title: Asking for information on the 2013 term Fall PhD enrolling.

(5) Would you please offer me some information, such as how many doctoral students you plan to enroll, and whether you plan to enroll international students?

Second, Ming stresses his own interest in the following ways:

(6) ... and find myself very interested in your project.

(7) ... I find it appealing to me...

(8) I am quite interested in your research areas...

The structure of "I"+predicate implicates a strong agency towards self, that is, it is "I" who takes interest in your project, instead of that "you attract me". Unlike some participants who read the targeted supervisors' paper on purpose, Ming said "I read some of your recent papers, ..., by chance". The modal phrase of "by chance" creates an impression that Ming came across the professor's work all by accident and his intended bonding with the professor was not that strong. Furthermore, when talking about his intention of application, he further 
downplayed his words: “..., if possible, I intend to apply for the PhD program in your research group". The engagement element of "if possible" softens Ming's determination, creates a little distance, and meantime shadows the relationship between Ming and Professor Smith.

The three types of discursive practices-prominent "I", implicit representation and shadowing "I \& You"-construct an overwhelming "I"-image for the audience, a modestly competent applicant driven by self-agency. Two factors can explain the dominance of "I". First and foremost, it is the initial email between Ming and Professor Smith. Ming knew partial information about Professor Smith from the faculty's bio website while Professor Smith had no idea about Ming. Thus, this email functions like a CV to bring Ming to the spotlight. It is understandable that the email attempts to provide as much information about the applicant as possible. Second, back then it was still an earlier phase for application. Most applicants were still preparing for their language examination and hadn't decided yet which specific professor they wanted to apply for. So was Ming. What's more, an offer wouldn't be that hard-earned for an excellent student in a prestigious university as in Interview 1 Ming reflected:

I didn't pay serious attention to the application issue at that time... ... I was hardly aware of it. But my hardware [academic performance, GPA, research work] is quite satisfying... I always thought application is simply easy and I made little effort to bond up with the professor (Interview 1).

\section{$5.2 I_{(\text {to you })}$ Identity in M-Email 4}

The email labeled as "M-email 4" was sent on March 7, 2014. At that time, the online application ended long since and applicants began to receive offer or rejection from American universities. This email contains four paragraphs too. The first paragraph is a brief self-introduction and an update of Ming's application status. Paragraph 2 mainly expresses Ming's eagerness to join Professor Smith's lab. The next paragraph mentions the applicant's commitment to the lab team. The last paragraph is about an urge followed by a determined promise.

\subsubsection{Dominant "I"s with an Emerging a "We"}

Once more, the pronoun of "I" still features most of the clauses as the Table 3 shows.

Table 3. Subject+predicate string in M-email 4 (clause-based)

\begin{tabular}{|c|c|c|}
\hline Para. & Subject+predicate & $\begin{array}{l}\text { Total } \\
\text { occurrence }\end{array}$ \\
\hline Para. 1 & I am...; we have ...; I'm writing...; I'm anxiously waiting...; I've submitted ...; I did not hear...; & 30 \\
\hline Para. 2 & $\begin{array}{l}\text { Your research group...; I've been thinking...; I should do...; I love...; doing research can satisfy...; I always } \\
\text { hoped ...; I won ...; I was...; I am very skilled ...; my major GPA rank ...; I feel...; my power is not ...; I } \\
\text { know ...; the study requires ...; the study requires ...; the (your) research content makes me...; I am really } \\
\text { longing for ...; }\end{array}$ & \\
\hline Para. 3 & I am confident ...; I can contribute...; I mentioned...; I have a lot of ...; please reference to...; & \\
\hline Para. 4 & what I need is ...; I won't ... & \\
\hline
\end{tabular}

Among the 30 clauses, there are 21 "I" subjects and two subjects ("my major GPA rank" and "my power") are Ming-relevant. Compared to the 16 out of $19(85 \%)$ in the first email, the proportion of 21 out of $30(77 \%)$ still takes a major account and contributes to the "I" identity. However, a careful examination of the pronouns breathes in new significance.

In the very second clause ("We've been connected through Email before"), there is a "we" pronoun, which is the first indicator of involving Ming and Professor Smith together. The plural "we" were examined under the term of positive face (e.g., Brown \& Levinson, 1987), solidarity (Scollon \& Scollon, 2001) or rapport (Spencer-Oatey, 2007). It signifies an emerging common ground, which is built up along the communication process. Since the applicant and the gatekeeper had several rounds of email exchange, it becomes a social fact that the two parties are connected and this fact can be reflected through "we". What's more important, this emergent "we" functions as a rapport strategy for further contacts. Just as Schiffrin comments, "what language thus allows us to do is represent what I and others have already said and done (or will say and do) in a textual world that can be reflected or acted upon, denied or supported, desired or dreaded, in the social worlds in which we are currently speaking and doing" (Schiffrin, 2006, p. 129). Therefore, "we" both symbolizes the established contacts and constructs Ming's intended connection with the advisor. 


\subsubsection{Manifesting the "I to You" Connection}

Compared with the more egocentric "I" in the first email, there is more ink spilled on the "I-You" dyad.

First Ming highlights the magnetic attraction from the Professor Smith as in the following sentences.

(9) Your research is my dream group.

(10) ... my power is not fully utilized until I know your group.

(11) The research content in your group makes me feel energetic.

Ming claimed that Professor Smith's research team was his dream group. The phrase of "dream group" is a highly positive appreciation term to acknowledge the value of Professor Smith's lab. So is the effect of "my power is not fully utilized until I know your group" and "your group makes me feel energetic". These positive appreciation elements are explicit compliment towards the supervisor. They constitute the reason for Ming to choose Professor Smith's team as his future group.

Second, since Professor Smith's lab emitted such an academic charm, Ming correspondently delivered an obvious willingness to be "attracted", manifesting more "I-to-you" bonding.

(12) ... and I am really longing for doing research under your instruction.

(13) ... I can contribute a lot to your team.

(14) Now what I need is a chance offered by you.

(15) I won't let you down.

The modulation expression "longing for" with an upgrader of "really" intensifies Ming's strong desire to be recruited as a part of the dream team. The emphatic structure of "what I need is..." serves as a direct request with high-weighted imposition, but it also depicts a keen applicant. The promise speech act of "contribution" and "I won't let you down" shows the applicant's firm determination to join the team.

All of the above-mentioned clauses contain a "I-You" dyad in the syntactic form of "your... my", "my... I ... your", "your...me", "I...your", "I...your", "I...you", or "I...you”. The co-occurrence of the two parties within one clause is a clear sign of the interaction between the two parties, "which helped to shape an involved relation and thus, shorten the distance between the writer and the professor" (Chen, 2001, p. 16). Even the email is entitled with "recommend myself to be your PhD student". After all this "I-You" interaction originates from Professor Smith's attraction to Ming.

Third, this email shows Ming's better understanding about Professor Smith's research as he appraised the research field.

(16) The study on Electro-magnetic and photonics requires the comprehension in physics and the skill in programming and simulation; the study on material structure and photolysis requires knowledge in chemistry. The research content in your group...

Although Ming didn't articulate this clearly, the underlined anaphoric phrase of "the research content in your group" indicates the previous two clauses were talking about the supervisor's research. This shows that Ming had more knowledge of Professor Smith's work, binding up himself with the supervisor closer. This detail is scaffold by the transcript of Interview 1.

Before, I was too lazy, to read professors' articles. I just browsed their websites and knew their research direction roughly, learning some key words and didn't read their articles ... But then, I took it seriously and began to read their articles very carefully and get to know what they are really doing (Interview 1).

\subsubsection{Explicit Self-Evaluation with Upgraders}

Contrasting to the sparse self-evaluation terms, this text is full-blown with sweet words about self. The words of "love" and "confident" contain a strong affection and indicates Ming's devotion to research work. The adjective "skilled in" plus an upgrader of "very" shows his skill in programming, the "top 10\%" GPA ranking proves his excellent course performance; "a lot of practical experiences" implies that Ming is an experienced researcher. The graduation terms of "not fully", "only" and "always" together with their respective semantic components give a hint at Ming's academic potential in the future.

(17) I love doing research;

(18) I am confident that ...

(19) I am also very skilled in; 
(20) I have a lot of practical experiences

(21) ... my major GPA rank top $10 \%$;

(22) ... my power is not fully utilized;

(23) only research can satisfy my curiosity;

(24) I always hoped to do ...

We can see a confident applicant, bold enough to claim his own advantages. Compared with the humble self-representation in the first email, Ming painted himself a more forceful "I"-portrait for the email reader, echoing English learners' self-expressing in email writing (Markley, 1992).

The afore-mentioned discursive practices add a more "relational" aspect to the "I" identity, since Ming instantiated linguistically "we" pronoun, "I-to-You" dyad in clause structure, and more content concerned about the supervisor. The strategic change can be harked back to Professor Smith's attraction power, which drives Ming to "long for" and "contribute to" his research team. Therefore, the "I $I_{\text {to you }}$ identity" is constructed.

The modification of self-representation in Ming-email 4 may be due to the following reasons. First, the deadline of final offer is coming. Each applicant cannot afford to play the zig-and-zag game. Everyone needed to show their real purpose in writing the email and convinced the gatekeeper their competence and ability. So, the email title is changed into "recommend myself to be your PhD student". Ming makes direct and positive appraisal about himself. Second, Ming was getting familiar with Professor Smith's research work as he dug deeply into the supervisor's work. He wanted to give a serious shot on this university. In the interview 1, Ming revealed that he spent a long time composing the email, almost two hours. Accordingly, we see more eagerness and devotion in Ming's discourse. This $I_{(\text {for you }}$ identity seems to already convince Professor Smith as he replied "How likely would you come to X University if we made an offer to you?"

\section{$5.3 I_{(\text {and you })}$ Identity in M-Email 6}

The email numbered as "M-email 6" was sent on April 8th 2014. Usually, April 15 is the last day for offer issuing to the Chinese students. If no offer comes on or before that day, it means a failed application.

The email consists of four parts. Paragraph 1 is a short self-identification. Paragraph 2 talks about what Ming can contribute to Professor Smith's lab. Paragraph 3 is about Ming's personal ambition for research work. The last paragraph is an inquiry about the supervisor's decision. This email differs from the previous one to construct a worthy collaborator in relation with the lab leader.

\subsubsection{Subject+Predicate Distribution: Less "I" Subjects}

A list of subject+predicate string in each paragraph is provided below.

Table 4. Subject+predicate string in M-email 6 (clause-based)

\begin{tabular}{|c|c|c|}
\hline Para. & Subject+predicate & Total \\
\hline Para. 1 & I'm...; I'm writing ...; & 31 \\
\hline Para. 2 & $\begin{array}{l}\text { research on ... is...; research on ... is ...; it requires ...; I think...; my research background can facilitate ..; my } \\
\text { experience on ... can be used ...; SPs is ...; you use ...; I investigated ...; a source generates ...; I studied ...; } \\
\text { those experience will help ...; }\end{array}$ & \\
\hline Para. 3 & $\begin{array}{l}\text { I wish; I could; researches can combine ...; Your group could be ...; I think; water photolysis is ...; I lived; *** } \\
\text { (place name) is...; The pollution is ...; solar fuel generation is ...; there would not be ...; I wish...; I could...; }\end{array}$ & \\
\hline Para. 4 & I want to...; the deadline of $\mathrm{PhD}$ application is ...; I have to ...; I attached ... & \\
\hline
\end{tabular}

First, there is a conspicuous change of subject distribution. Among 31 clauses, 16 subjects (51\%) are the email sender relevant, within which 14 are "I" subjects. The proportion of "I" subject (45\%) drops significantly compared with the previous two email episodes (69\% and 70\% respectively in M-email 1 and in M-email 4). On the contrary, there are more "you" and "you" relevant subjects: "research on surface plasmons", "research on SPs" and "it" in the second paragraph referring to Professor Smith's research work, "you" in the second paragraph and "your group" in the third paragraph. This more evenly distributed subject pattern creates a balanced view about "you and I" relation between the applicant and the applicantee.

Second, there are more predicates oriented to the future.

(25) ... those experience will help ... 
(26) ... my research background on optics and photonics can facilitate ...

my experience on programming and simulation of optical problems can be used ...

(27) I wish I could do ...

(28) I wish I could contribute ...

There is a tense-signifying modal verb "will" in (24), which is the only future tense used among the three texts. Although "can" and "could" indicates possibility and "wish" to modulation, all of them point to the future about what Ming would (or might) do if enrolled. The semantic content of these predicates are also future-oriented. It refers to what academic contribution that Ming could bring to Professor Smith's lab. Unlike the first email where "who I am/was" is magnified, there is more "who I can be" to you. However, this "I-You" dyad is not only based on a pure attraction from the professor as the case in M-email 4, but more on a possible perfect partnership between them as the next section shows.

\subsection{2 "You and I" Collaborating}

As it is expounded, the first email counts on facts enumeration to prove personal competence (M-email 1) and the second case makes a good use of explicit self-evaluation with upgraders to convince the supervisor (M-email 4). This email resorts to a discussion rhetoric to make persuasion.

Paragraph 2 starts with the current research focus (SPs) in Professor Smith's lab and emphasizes its interdisciplinary nature. Since Ming has that interdisciplinary background, he becomes a promising candidate for the spot. Ming further proves himself as a perfect fit with two exemplification arguments, which specify his possible contribution for different aspects of that research. The overall logical moves (clause-based) are structured as follows:

(a) Major premise 1: SPs is an important part of your lab.

(Clause 1)

2: SPs requires interdisciplinary knowledge.

(Clause 2, 3)

(b) Minor premise: My background is interdisciplinary

(Clause 5)

(c) Syllogism: I can facilitate SPs research.

(Clause 4, 5)

Exemplification 1: my experience A can be used for part one of SPs.

(Clause 6,7)

Exemplification 2: my experience B can be used for part two of SPs.

(Clause 8, 9, 10, 11, 12)

The lucid deduction rhetoric itself indicates a sensible mind or a typical science mind, and more importantly demonstrates Ming's incisive understanding of the supervisor's research focus. Instead of emphasizing the magnetic attraction (which constitutes the "I-to-You" dyad), this rhetoric produces a trustworthy collaborator, in the way that "I, an applicant, understand well what you are doing" and that makes "me" a perfect fit in "your" lab. This effect is boosted by the semantic content of "what I can bring to your lab" with upgraders (a lot). Moreover, Ming's intention to do research work for Professor Smith's lab matches his personal academic ambition as he explained in the third paragraph (Example 28, 29), which will create a win-win cooperation between the two parties.

(29) I wish I could do some interdisciplinary researches so that I can combine my knowledge...

(30) I wish I could contribute my power to this great job.

\subsubsection{Direct Speech Act}

The phrasing of request speech act is quite explicit since Ming uses direct speech act to utter clearly his purpose.

(31) I am writing to tell you my interest to [in] your group...

(32) I want to ask about your attitude toward my application to be your PhD student.

Example (30) is the second sentence in the email after the self-identification. It declares Ming's intention to be recruited in Professor Smith's group. Example (31) is the first sentence in the last paragraph. Usually in a research $\mathrm{PhD}$ program, the professor would act as the first gatekeeper before the application goes to the committee. Ming understood that if there was no positive answer from Professor Smith, his application might well go bankrupt. Thus, he directly asked for the supervisor's opinion about his application. These speech acts differ from those in the first email and M-email 4. Correspondently, the openness of request ushers in a frank response from Professor Smith-“I'll let you know on [date]. Is that ok? Can you wait that long?" This reply indicates that the professor did hold a positive attitude towards Ming's application. More common ground was promisingly built up and "I-and-You" dyad is probably going to turn into a real academic cooperation. 
In summary, the foregoing analysis adds new features to the I-identity. There is a balanced subject distribution, with more information oriented to the email recipient. There is less eagerness, but more rational logic. Chief among them is more "I \& You" interaction based on a possible collaboration and open frankness to each other. Likewise, these textual features boil down to some extra-discourse factors, including the application status, Ming's adjusted attitude towards application, and getting writing tips from his Chinese supervisor, as he reflected in Interview 1.

"After that [no good offer] I began to take it seriously... I wrote it again and gave it to my supervisor here for advice. He said my writing couldn't work. There are also students writing email to him and a first look will show who you are. He said advisors expect that you should know my area very well ... At first I just wrote my own interest. My supervisor said you should tell the professor what you can bring to them, that is contribution. So I changed it again and again, about 4 to 5 times, and my supervisor helped me a lot. And I sent it later." (Interview 1).

Ming admitted that this was a background of writing the sixth email. We cannot deny that the represented $I_{\text {(and you }}$ identity has a stable or structural basis, i.e., the extraneous factors. However, the discursive way it is performed in front to its audience testifies to the constructive power of bricks of language.

\section{Discussion}

"Relational identities are ... what people monitor most to see if a relationship is improving or disintegrating" (Tracy, 2002, p. 19). The first email profiles a competent candidate. The whole text is invested in the construction of "who I am" with the least regards to a specific audience. The "relation" between Ming and Professor Smith is comparatively distancing because the discursive practices instantiated cater for a group of potential supervisors in the relevant field. In other words, $I_{(\text {maxium })}$ identity is sculptured for whoever has an interest in "me", as Ming reflected that he sent it to several professor with just a modification of the name and research area. In the fourth email, a strong emotional bond is developed as Ming stresses the attraction from Professor Smith and his determination to join that research group. The content turns more specific and oriented towards Professor Smith. It aims at pulling closer the relationship between the two. The sixth email, which negotiates $I_{(\text {and you }}$ identity, presents us a promising cooperation between Ming and the professor since Ming could fit best in the interdisciplinary research topic. An equality (i.e., collaborating colleagues) is constructed though there might never exist equality between an applicant and the gatekeeper. Apparently, Ming's selection of discursive practices is more and more designed to accommodate for the audience (Giles, 1973, 2009; Bell, 1984).

The dynamic relational identities enacted bear inseparability from those extra-linguistic parameters. These situational factors on the one hand influence what and how Ming chose his wording strategy; on the other hand, his discursive choices were orchestrated to change his status quo and achieve the Taoci purpose, "in order to accomplish some and ends and to avoid others" (Tracy, 2002, p. 30). Although there are linguistic mistakes in Ming's English writing, like misspelling, inaccurate grammar, or even inappropriate usage of imposing speech act, these errors didn't hinder Ming's message from getting through to Professor Smith. Even with English as a foreign language to Ming, the textual lines present us a confident English user, countering the findings in Pan (2011).

The three "I"-identities in relation to the supervisor embed an insurmountable structural power difference between the applicant and the gatekeeper. The "I" constructed specially for "you" is the best proof. Whether this power imbalance is intended or not, it exists with or without individual awareness, because "everything we do in the course of a day communicates our relative power, our desire for a particular sort or connection, our identification of the other as one who needs something from us, or vice versa" (Lakoff, 1990, cited in Dervin \& Risager, 2014, p. 16). What Ming succeeded in is hardly the change of the stable power difference, but improving the common ground, alignment or solidarity with Professor Smith and turning the intended discursive relationship into a real-life institutional student-faculty relationship at the end. And this would exert a lingering effect in Ming's future construction of his master identity (possibly becoming an American), personality and his course of life.

\section{Conclusion}

This paper has studied the identity construction across three Taoci English emails written by the same Chinese student to his supervisor. Micro-interactional linguistic features in email are explored for the discourse identities and macro-situational factors are retrieved from interview transcripts to scaffold the argument. Through the analysis and interpretation, we present how linguistic features and extra-linguistic parameters are inter-wined. Limitations of this study are as follows. For example, interviews were not done immediately after the research 
participant contacted his supervisor, which might incur validity problem for postponed memory. Moreover, the response email from Professor Smith was obtained from the Ming. It might not capture the original wording. Future work could go beyond a case study of relational identity and explore other aspects of identity with more research participants. This would help to collect a more colorful picture of Taoci-er identity and give insights into the successful communication conducted in English email by Chinese mainland students.

\section{Acknowledgements}

I really appreciate the generous share from my research participant in this paper, without which the present research is impossible to be finished. Gratitude also goes to the funding from Chinese Scholarship Council in 2014-2015. I would like to thank Prof. Yihong Gao of Peking University, Dr. R. Sanders and Dr. I. Kecskes of SUNY at Albany, and anonymous reviewers for giving me valuable suggestion for the draft.

\section{References}

Bell, A. (1984). Language style as audience design. Language in Society, 13(2), 145-204. https://doi.org/10.1017/S004740450001037X

Benwell, B., \& Stokoe, E. (2006). Discourse and identity. Edinburgh: Edinburgh University Press.

Biesenbach-Lucas, S. (2007). Students writing e-mails to faculty: an examination of e-politeness among native and non-native speakers of English. Language Learning and Technology, 11(2), 59-81. http://dx.doi.org/10125/44104

Biesenbach-Lucas, S., \& Weasenfoith, D. (2001). Institutional discourse in the real world: Professors' judgements of student requests. Paper presented at the Georgetown University Roundtable of Languages and Linguistics (GURT).

Bloch, J. (2002). Student/teacher interaction via the social context of Internet discourse. Journal of Second Language Writing, 11(2), 117-134. https://doi.org/10.1016/S1060-3743(02)00064-4

Brown, P., \& Levinson, S. (1987). Politeness: Some universals in language usage. Cambridge: Cambridge University Press. https://doi.org/10.1017/CBO9780511813085

Burke, P. J., \& Stets, J. (2009). Identity Theory. New York: Oxford University Press. https://doi.org/10.1093/acprof:oso/9780195388275.001.0001

Chen, C. E. (2001). Making e-mail requests to professors: Taiwanese vs. American students. Paper presented at the Annual Meeting of the American Association for Applied Linguistics (St. Louis, MO, February 24-27, 2001). Retrieved from http://www.eric.ed.gov/contentdelivery/servlet/ERICServlet?accno=ED461299

Chen, C. E. (2003). The use of email for interpersonal communication in a second language: A comparative case study of two Chinese speakers' email practices in English. Unpublished doctoral dissertation. State University of New York at Albany, Albany, US.

Chen, Y. S. (2015). Developing Chinese EFL learners' email literacy through requests to faculty. Journal of Pragmatics, 75, 131-149. https://doi.org/10.1016/j.pragma.2014.05.009

Danielewicz-Betz, A. (2013). (Mis)use of e-mail in student-faculty interaction: implications for university instruction in Germany, Saudi Arabia and Japan. Jaltcall Journal, 9(1), 23-57. https://doi.org/10.29140/jaltcall.v9n1.147

Dervin, F., \& Risager, K. (2014). Introduction. In F. Dervin \& K. Risager (Eds.), Routledge Studies in Language and Intercultural Communication: Researching Identity and Interculturality (pp. 1-25). New York: Taylor and Francis. https://doi.org/10.4324/9781315816883

Economidou-Kogetsidis, M. (2011). "Please answer me as soon as possible": pragmatic failure in non-native speakers' e-mail requests to faculty. Journal of Pragmatics, 43(13), 3193-3215. https://doi.org/10.1016/j.pragma.2011.06.006

Giles, H. (1973). Accent mobility: A model and some data. Anthropological Linguistics, 15, 87-105.

Giles, H. (2009). The process of communication accommodation. In N. Coupland \& A. Jaworski (Eds.), The New Sociolinguistics Reader (pp. 276-286). New York: Bloomsbury Publishing PLC. https://doi.org/10.1007/978-1-349-92299-4_19

Goffman, E. (1967). Interactional Ritual: Essays in Face-to-face Behavior. Chicago: Aldine Publishing Company.

Hartford, B. S., \& Bardovi-Harlig, K. (1996). "At your earliest convenience": A study of written student requests 
to faculty. In L. Bouton (Ed.), Pragmatics and language learning (vol. 7, pp. 55-69). Retrieved from https://files.eric.ed.gov/fulltext/ED400704.pdf

Herring, S. C. (2002). Computer-mediated communication on the Internet. Annual Review of Information Science and Technology, 36, 109-168. https://doi.org/10.1002/aris.1440360104

Kecskes, I. (2006). On my mind: thoughts about salience, context and figurative language from a second language perspective. Second Language Research, 22(2), 219-237. https://doi.org/10.1191/0267658306sr266ra

Markley, P. (1992). Creating independent ESL writers and thinkers: Computer networking for composition. CAELL Journal, 3(2), 6-12.

Merrison, A. J., Wilson, J. J., Davies, B., \& Haugh, M. (2012). Getting stuff done: comparing e-mail requests from students in higher education in Britain and Australia. Journal of Pragmatics, 44(9), 1077-1098. https://doi.org/10.1016/j.pragma.2012.05.009

Pan, P. (2010). Making requests in institutional e-email communication in Hong Kong: An interlanguage and intercultural pragmatics approach. Unpublished doctoral dissertation. Chinese University of Hong Kong, Hong Kong, China.

Schiffrin, D. (2006). From linguistic reference to social reality. In A. De Fina, D. Schiffrin \& M. Bamberg (Eds.), Discourse and Identity (pp. 103-131). Cambridge: Cambridge University Press. https://doi.org/10.1017/CBO9780511584459.006

Scollon, R., \& Scollon, S. W. (2001). Intercultural communication: A discourse approach (2nd ed.). Malden, Mass.: Blackwell Publishers.

Sheer, V. C., \& Fung, T. K. (2007). Can email communication enhance professor-student relationship and student evaluation of professor? Some empirical evidence. Journal of Educational Computing Research, 37(3), 289-306. https://doi.org/10.2190/EC.37.3.d

Tracy, K. (2002). Everyday talk: Building and reflecting identities. New York: Guilford Press.

Xiao, L. (2014). Rapport management in Chinese "Taoci" email. Linguistic Research, 15, 165-174. Retrieved from http://www.cnki.com.cn/Article/CJFDTotal-YUYA201401015.htm

Xiao, L. 2022. Speech act as investment: A study on the discourse practice of Taoci. Hangzhou: Zhejiang Gongshang University Press. (in press)

Xiao, L., \& Gao, Y. (2015). Intercultural Taoci email: New wine in the old bottle. In Y. Chen, D. V. Rau \& G. Rau (Eds.), Chinese university students' email discourse in academia: An ELF pragmatic perspective (pp. 135-162). Singapore: Springer Publisher. https://doi.org/10.1007/978-981-287-888-5_7

Zhu, H. (2014). Interculturality: Reconceptualising cultural memberships and identities through translanguaging practice. In F. Dervin \& K. Risager (Eds.), Routledge studies in language and intercultural communication: Researching identity and interculturality (pp. 109-124). New York: Taylor and Francis.

Zhu, W. (2012). Polite requestive strategies in emails: an investigation of pragmatic competence of Chinese EFL learners. RELC Journal, 43(2), 217-238. https://doi.org/10.1177/0033688212449936

\section{Notes}

Note 1. Baidu Baike is a Chinese version of online encyclopedia. Taoci is a term which overseas education applicants are quite familiar with. It specifically refers to applicants' personal email contacts with their targeted supervisors so as to increase admission and scholarship opportunities. (Retrieved from http://baike.baidu.com/view/1385927.html)

\section{Copyrights}

Copyright for this article is retained by the author, with first publication rights granted to the journal.

This is an open-access article distributed under the terms and conditions of the Creative Commons Attribution license (http://creativecommons.org/licenses/by/4.0/). 